\title{
Assessment of gesture behavior and knowledge on low back pain among nurses

\author{
Hisa Costa Morimoto ${ }^{1}$, Anamaria Jones ${ }^{1}$ and Jamil Natour ${ }^{1,2^{*}}$
}

\begin{abstract}
Background: Low back pain is particularly problematic among nursing professionals. Education is part of the rehabilitation process for low back pain and has been heavily studied. In parallel, gestural behaviors play an important role during the evaluation of the low back pain, especially while performing the activities of daily living. The aim of the present study was to evaluate gesture behavior and knowledge on LBP among nurses with and without LBP and correlate these factors with pain, physical functioning and quality of life.
\end{abstract}

Methods: An observational, controlled, cross-sectional study was carried out in 120 female nurses: 60 with LBP and 60 without LBP. The two groups were matched for age. The measures used for the evaluation were the Gesture Behavior Test, LBP Knowledge Questionnaire, Numerical Pain Scale for LBP, Roland Morris Disability Questionnaire and the Short Form-36 (SF-36) to assess quality of life.

Results: Mean age in both groups was 31 years. In the group with LBP, the mean Numerical Pain Scale score was $5.6 \mathrm{~cm}$ and the mean score on the Roland Morris questionnaire was 2.7. No statistically differences between groups were found regarding the scores of the LBP Knowledge Questionnaire or Gesture Behavior Test ( $p=0.531$ and $p=0.292$, respectively). Statistically lower scores were found in the group with LBP for the following SF-36 domains: physical functioning $(p<0.001)$, physical role $(p=0.015)$, pain $(p=0.001)$, general health perceptions $(p=0.015)$, vitality $(p<0.001)$ and mental health $(p=0.001)$.

Conclusions: No differences were found when comparing nurses with or without LBP regarding gesture behavior or knowledge on LBP. Nurses with LBP showed a decrease in some domains of quality of life.

Keywords: Low back pain, Nurses, Behavior and patient's knowledge

\section{Background}

Low back pain is one of the most painful disorders, it is also a common cause of morbidity and is associated with significant social and economic impact worldwide. Epidemiological studies indicate that the prevalence of low back pain in the general population is between 60 and $80 \%[1,2]$. The literature reports that $90 \%$ of adults will experience back pain at least once in their lives [1, 3].

Low back pain is particularly problematic among nursing professionals in terms of absenteeism and litigation processes; it is also an important source of morbidity in this population. Its prevalence seems to be higher among nurses and nurses' aids than in the rest of the population, ranging between 56 and 90\% respectively. Emotional stress, physical and psychosocial factors at work are crucial to the onset of low back pain [4-6].

\footnotetext{
* Correspondence: jnatour@unifesp.br

'Rheumatology Division, Universidade Federal de São Paulo, São Paulo, Brazil ${ }^{2}$ Disciplina de Reumatologia, Rua Botucatu, 740, Sao Paulo, SP 04023-090, Brazil
}

Flexion, twisting, weight transfer and sudden movements were related to low back pain [7]. Similar findings were observed in another study, considering hoisting associated with spinal twisting, previous injury and excess of weight as risk factors for low back pain in nurses [8].

In 2008, researchers conducted a cross-sectional study of nurses with an average age of 26 years, in which they assessed the risk of developing low back pain due to occupational exposure in new nurses and students [9]. They concluded that over the course of one year in the profession, the risk of experiencing an increase in back pain was $90 \%$, suggesting that the act of transferring patients in bed was detrimental and that preventive strategies should be aimed at this population.

Education is part of the rehabilitation process for low back pain and has been heavily studied. In parallel, gestural behaviors play an important role during the evaluation of the low back pain, especially while performing the activities of daily living (ADLs). Assessment 
instruments, such as the low back pain knowledge questionnaire (LKQ) and the gestural behavior test (GBT), were created and validated to expand the ways to evaluate the patient in a more specific manner $[10,11]$. Because gestural behavior and knowledge of the disease are important variables in the management of low back pain, the aim of the present study was to evaluate the gestural and knowledge of low back pain in nurses with low back pain and compare with nurses without low back pain, as there are no studies in the literature for this purpose.

\section{Methods}

\section{Sample}

A hundred twenty nurses from the Hospital Sao Paulo - Universidade Federal de São Paulo / Escola Paulista de Medicina (UNIFESP / EPM) were included: 60 nurses with low back pain and 60 nurses who served as controls without back pain. The nurses in the control group were matched by age with the low back pain group. The study was approved by the Ethics and Research Committee of the University.

Sample size was calculated using GBT as the main parameter, with a standard deviation of 5 points.11 For the determination of a minimal difference of 3 points between groups among healthcare professionals, a 5\% $\alpha$ error and a power of $90 \%$ were established. The calculation determinate a minimal sample of 60 nurses per group.

The low back pain group included nurses in activity, aged between 22 and 60 years, working in different hospital sectors (wards, emergency room and/or intensive care units) with a minimum workload of $6 \mathrm{~h}$ /day who experienced back pain on most days during the last three months, with a report of pain greater than $3 \mathrm{~cm}$ on a numerical pain scale (NPS) $0-10 \mathrm{~cm}$. The control group included nurses with the same features but without back pain.

Nurses in situations of dispute, with prior surgery of the spine and/or a current pregnancy, were excluded from the study.

\section{Outcomes}

The participants completed an evaluation form with demographic (age, marital status, body mass index), clinical and professional information (disease duration and time since graduation), information's regarding smoking habits and life style and applied assessment tools to specify the level of low back pain. Almost all questionnaires were self-applied, only the GBT evaluation, was done by evaluator not blinded.

The assessment instruments used included the following:

- Gesture Behavior Test (GBT): this test evaluates the gestural behavior of patients with chronic non- specific low back pain. It consists of five functional tasks:

$\bigcirc$ Task 1: getting out of bed after sleeping;

$\bigcirc$ Task 2: sweep under the bed;
Task 3: lift and carry a garbage disposal;

Task 4: simulate tying shoelaces without help;

Task 5: organize objects with various weights on shelves of various heights.

Each task is characterized by an instruction, allowing several standardized scoring criteria. The score ranges from 0 to 32, with a higher score indicating a better gestural behavior [11].

- Low Back Pain Knowledge Questionnaire (LKQ): this instrument assesses knowledge about back pain. Composed of 16 questions, divided into the following categories: general aspects, concepts and treatment. The score ranges from 0 to 24 points, with a higher score denoting a better knowledge of low back pain [10].

- Numerical Pain Scale (NPS): this instrument subjectively assesses pain. The nurse quantifies the intensity of low back pain following a line of $0-10 \mathrm{~cm}$, 0 being no pain and 10 being unbearable pain [12].

- Roland Morris Disability Questionnaire (RM): this instrument assesses the functional disability in patients with low back pain. It consists of 24 questions of self - response (yes or no), and the score ranges from zero (no disability) to 24 points (severe disability) [13].

- Short Form - 36 (SF-36): generic questionnaire that assesses quality of life, with 36 items about general health that fall into eight domains: physical functioning, role limitations due to physical health, bodily pain, general health, vitality, social health, emotional health and mental health. The score for each domain ranges from 0 to 100 , and higher scores indicate a better quality of life [14].

\section{Statistical analysis}

The statistical program SPSS 19.0 was used. The level of significance was set to 0.05 .

Descriptive statistics were presented by the frequency and percentage for categorical data and the mean with standard deviation for quantitative data. The KolmogorovSmirnov test was applied to assess the normality of the variables. To evaluate the homogeneity of the sample at baseline, chi-square tests, Student t-tests and Mann-Whitney tests were performed. The Spearman correlation test was used to assess the quantitative variables $[15,16]$.

\section{Results}

Table 1 summarizes the mean and standard deviation (SD) of the sociodemographic data, demonstrating the homogeneity of the sample for these parameters. The mean age of total sample was 31.6 years. The groups were similar in terms of age, body mass index (BMI), 
Table 1 Sample characteristics

\begin{tabular}{llll}
\hline & LBP group & Control group & P intergrupo \\
& $N=60$ & $N=60$ & \\
\hline Age (years) & $31,7 \pm 7,8$ & $31,6 \pm 7,5$ & $0,979^{\mathrm{b}}$ \\
BMI $\left(\mathrm{kg} / \mathrm{m}^{2}\right)$ & $24,6 \pm 4,9$ & $23,5 \pm 3,2$ & $0,518^{\mathrm{b}}$ \\
Marital status & - & - & $0,727^{\mathrm{a}}$ \\
$\quad$ Single & $39(65 \%)$ & $41(68,3 \%)$ & - \\
$\quad$ Maried & $19(31,7 \%)$ & $16(26,7 \%)$ & - \\
$\quad$ Divorced & $2(3,3 \%)$ & $3(5,0 \%)$ & - \\
Time since graduation (years) & $7,2 \pm 6,9$ & $6,6 \pm 6,0$ & $0,983^{\mathrm{b}}$ \\
Disease duration (years) & $4,2 \pm 2,6$ & - & - \\
NPS (cm) & $5,6 \pm 1,7$ & - & - \\
Roland Morris & $2,7 \pm 2,5$ & - & - \\
\hline
\end{tabular}

Data presented as mean \pm standard deviation or percentage (\%) $B M I$ body mass index, NPS numeric pain scale, $p$ significance value in the comparison between groups

${ }^{a}$ chi-square test

${ }^{\mathrm{b}}$ Mann-Whitney

marital status and training time. The mean duration of symptoms in the low back pain group was 4.2 years. Table 1 also shows the NPS and RM scores of the low back pain group.

According to the lifestyle evaluation of the nurses, the groups were homogeneous regarding inactivity $(p=0.838)$ and smoking $(p=0.679)$. The proportions are presented in Table 2.

With respect to the variables of GBT and LKQ, we found no significant differences between the groups $(p=0.292$ and $p=0.531$, respectively). The means and standard deviation scores are presented in Table 3.

In the quality of life assessment using the SF-36, there were significant differences between the groups in the following domains: physical functioning $(p=0.001)$, role limitations due to physical health $(p=0.015)$, pain $(p<0.001)$, general health $(p=0.015)$, vitality $(p<0.001)$ and mental health $(p=0.001)$. There were no significant differences between the groups in the areas of social and emotional health (Table 4).

In Table 5 shows the statistically significant correlations between the SF-36 domains, LKQ and GBT scores in the

Table 2 Ratio of sedentary and smoking among nurses

\begin{tabular}{clll}
\hline & LBP group & $\begin{array}{l}\text { Control group } \\
N=60\end{array}$ & P intergrupo \\
\hline Sedentary & - & - & 0,838 \\
Yes & $44(73,3 \%)$ & $43(71,7 \%)$ & - \\
No & $16(26,7 \%)$ & $17(28,3 \%)$ & - \\
Smoking & - & - & 0,679 \\
Yes & $4(6,7 \%)$ & $2(3,3 \%)$ & - \\
No & $56(93,3 \%)$ & $58(96,7 \%)$ & -
\end{tabular}

Data presented as $\mathrm{n}$ and percentage (\%) using the Chi-square test $p$ significance value in the comparison between groups
Table 3 Scores of the Gestural Behavior Test (GBT) and Low Back Pain Knowledge Questionnaire (LKQ)

\begin{tabular}{llll}
\hline & $\begin{array}{l}\text { LBP group } \\
N=60\end{array}$ & $\begin{array}{l}\text { Control group } \\
N=60\end{array}$ & P intergrupo \\
\hline GBT & $17,7 \pm 3,9$ & $18,5 \pm 4,3$ & 0,292 \\
LKQ & - & - & - \\
General aspects & $8,2 \pm 1,0$ & $8,0 \pm 0,8$ & 0,217 \\
Concept & $3,1 \pm 1,1$ & $3,1 \pm 0,9$ & 0,867 \\
Treatment & $8,0 \pm 1,8$ & $8,0 \pm 1,7$ & 0,781 \\
Total & $19,2 \pm 3,1$ & $19,1 \pm 2,5$ & 0,531 \\
\hline
\end{tabular}

Data presented as mean \pm standard deviation using the Mann-Whitney test GBT gestural behavior test, $L K Q$ low back pain knowledge questionnaire, $p$ significance value in the comparison between groups

control and low back pain groups. No correlations were found between the RM, LKQ and GBT questionnaires.

\section{Discussion}

LBP is the most prevalent and costly musculoskeletal disorder worldwide. Studies in nurses with low back pain have reported strong associations among work environment, lifestyle and postural factors [17].

The aim of this study was to evaluate the gestures and knowledge of disease in nurses because the literature indicates that these variables are relevant in the perpetuation and management of low back pain.

Our study evaluated only nurses and not nurses aids. It is known that in Brazil, these professionals have distinct and unique roles, commonly involving activities that require constant movement of the lumbar spine, such as caring for patients in bed and performing transfers. However, a regulation imposed by the Board of Nursing describes the full range of functions for nursing professionals, which includes being exposed to physical and biomechanical factors that can trigger back pain. Therefore, to avoid bias, we chose to only evaluate nurses because each group has a professional profile and distinct function. The study evaluated nurses' aids and nurses within a single group [18].

d'Ericco et al. in 2013, investigated the prevalence of back pain and the association with absenteeism in nurses and concluded that the prevalence was $58.2 \%$, being $55.9 \%$ to chronic low back pain and $61.9 \%$ to acute low back pain. Relative to the nurses' aids, the prevalence was higher $(67.5 \%$ among the nurses and $36.4 \%$ among the nurses' aids) [19].

Our sample included only women to ensure a homogeneous sample by gender, as male hospital nurses represent a minority. Some of the other studies previously in the literature also opted for a heterogeneous sample by gender [20-22].

The average age of the nurses assessed was 31.7 years. These data are similar to Yip and Jaromi et al. studies 
Table 4 Evaluation of the SF-36 demonstrated as mean and standard deviation

\begin{tabular}{llll}
\hline & LBP group & Control group & P intergrupo \\
& $N=60$ & $9=60$ & $<0,001^{\text {a }}$ \\
\hline Physical functioning & $82,1 \pm 16,6$ & $91,8 \pm 9,1$ & $0,015^{\text {a }}$ \\
Role limitations due to physical health & $72,5 \pm 32,1$ & $84,2 \pm 26,4$ & $<0,001^{\text {a }}$ \\
Bodily pain & $56,4 \pm 16,2$ & $74,0 \pm 21,8$ & $0,015^{\text {a }}$ \\
General health & $74,7 \pm 15,6$ & $81,4 \pm 14,6$ & $<0,001^{\text {a }}$ \\
Vitality & $52,1 \pm 17,5$ & $64,3 \pm 16,0$ & 0,179 \\
Social Health & $74,8 \pm 20,9$ & $80,0 \pm 18,7$ & 0,970 \\
Emotional health & $72,8 \pm 35,0$ & $75,0 \pm 30,5$ & $0,001^{\text {a }}$ \\
Mental health & $66,5 \pm 16,7$ & $75,5 \pm 13,1$ &
\end{tabular}

Data presented as mean \pm standard deviation using the Mann-Whitney test

$p$ significance value in the comparison between groups

Value statistically significant

and are consistent with the literature, which places the age group with the highest incidence of low back pain between 18 and 65 years [23, 24]. A study by Sikiru \& Hanifa [22], showed that the prevalence of back pain increased with age. The group $<35$ years showed a prevalence of $6.3 \%$; the group $36-45$ years showed a prevalence of $27 \%$; and the group $>46$ years showed a prevalence of $66.7 \%$.

Other variables, such as physical inactivity and smoking, were also collected to characterize the sample. Physical inactivity and smoking, in association with other variables, have been reported as important factors for increasing the risk of low back pain [25]. In this study, $73 \%$ of the nurses were sedentary. In contrast, only $6 \%$ of the sample were smokers. In Vieira et al. [21] study, the nurses were less sedentary (55\%) but included more smokers (35\%). Yip found no significant correlation between inactivity and low back pain in nurses.
The GBT was the instrument chosen to assess the gestural behavior of the nurses. This test was initially created to evaluate the gestures of patients with chronic nonspecific low back pain who have participated in an educational program that typically consists of information on joint protection and energy conservation, as well as advice on spinal anatomy, conservative treatment, medication and disease management.

Importantly, the literature does not describe a specific test for evaluating the gestural behavior of nurses. The GBT does not evaluate gestures performed during the work activities of a nurse but rather those performed while simulating the activities of daily living. We believe that the behaviors that nurses adopt in their day-to-day will also adapt to their work environment.

Although this is a cross-sectional study and does not propose an educational intervention for nurses, it is interesting to evaluate the gestural behavior of this

Table 5 Correlations between of SF-36 domains, the Gestural Behavior Test (GBT) and Low Back Pain Knowledge Questionnaire (LKQ) scores in the control and low back pain groups

\begin{tabular}{|c|c|c|c|c|c|}
\hline SF-36 & LKQ -GA & LKQ -Concept & LKQ -Treatment & LKQ - Total & GBT \\
\hline \multicolumn{6}{|l|}{ Control group } \\
\hline Bodily Pain & NS & $0.270(0.037)$ & NS & NS & NS \\
\hline Global health & NS & NS & NS & NS & $0.290(0.024)$ \\
\hline Vitality & NS & NS & NS & NS & $0.290(0.049)$ \\
\hline \multicolumn{6}{|l|}{ LBP group } \\
\hline Physical functioning & NS & $0.258(0.047)$ & NS & NS & NS \\
\hline Bodily pain & $0.227(0.032)$ & NS & NS & NS & NS \\
\hline General health & NS & $0.312(0.015)$ & NS & NS & NS \\
\hline Social Health & NS & $0.269(0.038)$ & NS & NS & NS \\
\hline Emotional health & NS & NS & $0.268(0.038)$ & NS & NS \\
\hline Mental health & NS & NS & NS & $0.256(0.048)$ & NS \\
\hline
\end{tabular}

Correlations presented were statistically significant $(p<0.05)$

$L K Q$ low back pain knowledge questionnaire, GA general aspects, $L K Q$ low back pain knowledge questionnaire, $L B P$ low back pain, NS non significant 
population because the relationship between physical factors and low back pain has been heavily discussed in the literature, and to date, no other study has used this instrument.

Regarding the assessment of knowledge of the disease, the only specific questionnaire addressing low back pain in the literature is the LKQ. This is the first study to evaluate the knowledge of low back pain in nurses using the LKQ.

Sikiru \& Hanifa evaluated the knowledge of joint protection of the spine in 300 nurses with low back pain using a no validated questionnaire formulated by the authors themselves [22]. They observed that 80 nurses (26.6\%) exhibited knowledge about joint protection, whereas 220 (73.3\%) had no knowledge on this topic. There was a significant correlation between the knowledge of joint protection of the spine with the incidence of low back pain. In this study, it would be appropriate to use the LKQ that include issues regarding joint protection and energy conservation.

Pain and disability are important variables in the characterization of low back pain. There are many instruments that assess pain and functional disability in low back pain. For pain assessment, the NPS was chosen because of its easy application and improved understanding, and the RM was used to assess functional disability due to its status as a questionnaire widely used in the literature. The nurses presented an average pain level of $5.6 \mathrm{~cm}(\mathrm{SD}=1.7)$ and showed no severe disability according to the RM questionnaire. In a study by Lin et al. in 2012, nurses were evaluated using the Visual Analogue Scale (VAS) $0-100 \mathrm{~mm}$, and the average pain level was $41.6 \mathrm{~mm}$ [26]. With respect to functional disability, we cannot compare our data with those in the literature because we did not find any studies that evaluated low back pain in nurses and utilized the RM.

The quality of life, assessed using the SF-36, was worse in terms of functional capacity, role limitations due to physical health, bodily pain, general health, vitality and mental health in the low back pain group compared to the control group. Carugno et al. showed similar results to those of our study [27]. The authors used the mental health domain of SF-36 to evaluate 751 nurses and found that nurses with musculoskeletal disorders, including back pain, presented worse mental health. No studies that correlated the SF-36 with the instruments used in our study were found.

Regarding knowledge of disease and gestural behavior, we found no statistical differences between the groups. Regarding the GBT, the total average score in the two groups was 19 points, with a maximum score of 32 points. In a study by Furtado et al., the average score among all patients with low back pain was 16.3 , whereas rehabilitation professionals without back pain had a mean score of
26 points. Despite the smaller scores within the general population, these results are similar to those of nurses, indicating a low level of knowledge in this area even among health professionals [11].

Regarding the assessment using the LKQ, the mean score for nurses was 19 points, in a total score of 24 points. Maciel et al. [10] showed that the mean total score of patients with chronic low back pain was 9 points, far below the results observed for our sample.

Based on these results, we believe that both nurses with low back pain and the control group have a good level of knowledge about the important aspects of low back pain but do not use this knowledge in their day-to-day lives, resulting in behaviors that include inappropriate gestures. This line of thought further strengthens the importance and necessity of adopting a behavioral approach during the treatment of chronic nonspecific low back pain that includes disease management, adherence to therapy and conservative treatment, thereby improving both mental and physical behaviors.

Although the nurses showed no difference between gestural behavior and knowledge of the disease, we found positive (weak and moderate) correlations between some SF-36 domains with GBT and LKQ. These data reflect that the two variables are directly related to the quality of life, mainly in the physical aspects and vice versa.

We found no correlation between pain and disability using the GBT and LKQ. Similarly, a study by Furtado et al. [11], found no correlation between pain and GBT. However, our data showed a correlation between RM and GBT. The authors believe that the disability caused by chronic low back pain leads the patient to adopt copping towards protecting and not overloading the spine. It is likely that our results did not agree with those of the study by Furtado et al. because nurses with LBP have only low disability, according to the assessment by RM.

This study has some limitations, among them the small sample, the lack of men in the sample and also the lack of blind evaluator.

We believe that no difference was found between the groups in GBT and LKQ, because the nurses in the low back pain group did not show an important disability. As shown in the results, according to the RM, the nurses were classified as having mild disability. A possible explanation for RM results may be the level of knowledge of the sample, because it is a health professional and because of the classification of low back pain. The study chose to evaluate nurses with chronic low back pain. Perhaps in the acute phase, the results would be different from those presented in the present study. It is important to note that GBT is not specific to assess the disease's impairment. We believe that RM is more sensitive to evaluate this variable. 
As seen in the literature, there are few studies evaluating the variables evaluated in our study. Therefore, it is necessary that new controlled studies be carried out in order to deepen the use of these instruments and to corroborate the results of the present study; epidemiological studies with large samples to evaluate the prevalence of low back pain in nurses; and other studies with educational intervention.

\section{Conclusion}

Nurses with back pain do not show differences in behavior or in gestural knowledge about back pain when compared to nurses without low back pain. However, nurses with low back pain show less quality of life.

\section{Authors' contributions}

All authors contributed to conception and design of the study, analysis and interpretation of data, drafting the article and revising it critically for important intellectual content and final approval of the version to be submitted. HCM and AJ contributed with the data acquisition too.

\section{Ethics approval and consent to participate}

The study was approved by Ethical comitte of Universidade Federal de São Paulo (1586/08) and all patients signed the informed consent form. The study was also register at clinicaltrials.gov (NCT01556295).

\section{Consent for publication}

All the authors have read and approved the manuscript cited above after having been approved in the editorial process and consent with the publication.

\section{Competing interests}

The authors declare that they have no competing interests.

\section{Publisher's Note}

Springer Nature remains neutral with regard to jurisdictional claims in published maps and institutional affiliations.

Received: 20 August 2018 Accepted: 24 August 2018

Published online: 07 September 2018

\section{References}

1. Deyo RA, Weinstein JN. Primary care - low back pain. N Engl J Med. 2001; 344(5):363-70

2. Jaromi M, Nemeth A, Kranicz J, Laczko T, Betlehem J. Treatment and ergonomics training of work-related lower back pain and body posture problems for nurses. J Clin Nurs. 2012;21(11-12):1776-84.

3. Frymoyer JW, Pope MH, Constanza MC, Osen JC, Goggin JE, Wilder DJ. Epidemiologic studies of low back pain. Spine. 1980;5:419-23.

4. Maul I, Laubli T, Klipstein A, Krueger H. Course of low back pain among nurses: a longitudinal study across eight years. Occup Environ Med. 2003;60:497-503.

5. Smedley J, Trevelyan F, Inskip H, Bucle P, Cooper C, Coggon D. Impact of ergonomic intervention on back pain among nurses. Scand J Work Environ Health. 2003;29(2):117-23.

6. Eriksen W, Bruusgaard D, Knardahl S. Work factors as predictors of intense a disabling low back pain; a prospective study of nurses' aides. Occup Environ Med. 2004:61:398-404

7. Punnet L, Fine LJ, Keyserling WM, Hersen GD, Chaffin DB. Back disorders and nonneutral trunk postures of automobile assembly workers. Scand J of Work, Environ Health. 1991;17(5):337-46.

8. Fuortes L, Shi Y, Zhang M, Zwerling C, Schootman M. Epidemiology of back injury in university hospital nurses from review of workers compensation records and a case-control survey. J Occup Med. 1994. 36:1022-6.
9. Mitchell T, O'Sullivan PB, Burnett AF, Straker I, Rudd C. Low back pain chacteristics from undergraduate student to working nurse in Australia: a cross-sectional survey. Int J Nurs Stud. 2008;45(11):1636-44.

10. Maciel SC, Jennings $F$, Jones $A$, Natour J. The development and validation of a low back pain knowledge questionnaire - LKQ. Clinics. 2009;64(12):1167-75.

11. Furtado R, Jones A, Furtado RNV, Jennings F, Natour J. Validation of the Brazilian portuguese version of the gesture behavior test for patients with non-specific chronic low back pain. Clinics. 2009;64(2):83-90.

12. Ferraz MB, Oliveira LM, Araujo PM, Atra E, Tugwell P. Crosscultural reability of physicalability dimension of the health assessment questionaire. J Rheumatol. 1990a:17(6):813-7.

13. Nusbaum L, Natour J, Ferraz MB, Goldenberg J. Translation, adaptation and validation of the Roland-Morris questionnaire - Brazil Roland-Morris. Braz Med Biol Res. 2001;34(2):203-10.

14. Ciconelli RM, Ferraz MB, Santos W, Meinão I, Quaresma MR. Tradução para a língua portuguesa e validação do questionário genérico de avaliação de qualidade de vida SF-36 (Brasil SF-36). Rev Bras Reumatol. 1999;39(3):143-50.

15. Zar JH. Biostatistical analysis. Upper Saddle River: Prentice Hall; 1999.

16. Brunner E, Langer F. Nonparametric análisis of ordered categorical data in designs with longitudinal observations and small sample sizes. Biom J. 2000; 42(6):663-75.

17. Woolf AD, Pfleger B. Burden of major musculoskeletal conditions. Bull World Health Organ. 2003;81(9):646-56.

18. Hartvigsen J, Lauritzen S, Lings S, Lauritzen T. Intensive education combined with low tech ergonomic intervention does not prevent low back pain in nurses. Occup Environ Med. 2005:62:13-7.

19. d'Errico A, Viotti S, Baratti A, Mottura B, Barocelli AP, Tagna M, et al. Low back pain and associated presenteeism among hospital nursing staff. J Ocupp Health. 2013;55(4):276-83.

20. Yip VY. New low back pain in nurses: work activies, work stress and sedentary lifestyle. J Adv Nurs. 2004;46(4):430-40.

21. Vieira ER, Kumar S, Coury HJCG, Narayan Y. Low back problems and possible improvements in nursing jobs. J Adv Nurs. 2006:55(1):79-89.

22. Sikiru L, Hanifa S. Prevalence and risk factors of low back pain among nurses in a typical Nigerian hospital. Afr Health Sci. 2010;10(1):26-30

23. Leclaire R, Esdaile JM, Suissa S, Rossignol M, Proulx R, Dupuis M. Back school in a first episode of compensated acute low back pain: a clinical trial to assess efficacy and prevent relapse. Arch Phys Med Rehabil. 1996;77(7):673-9.

24. Glomsrod B, Loon JH, Soukup MG, Bo K, Larsen S. (2001). Active back school. Prophylactic management for low back pain: three year follow-up of a randomized controlled trial. J Rehab Med. 2001;33:26-30.

25. Bejia I, Younes M, Jamila HB, Khalfallah T, Bem Salem K, Touzi M, et al. Prevalence and factors associated to low back pain among hospital staff. Joint Bone Spine. 2005:72(3):254-9.

26. Lin PH, Tsai YA, Chen WC, Huang SF. Prevalence, characteristics, and workrelated risk factors of low back pain among hospital nurses in Taiwan: a cross-sectional survey. Int J Occup Med Environ Health. 2012;25(1):41-50.

27. Carugno M, Pesatori AC, Ferrario MM, Ferrari AL, Silva FJ, Martins AC, et al. Physical and psychosocial risk factors for musculoskeletal disorders in Brazilian and Italian nurses. Cad Saude Publica. 2012;28(9):1632-42.

Ready to submit your research? Choose BMC and benefit from:

- fast, convenient online submission

- thorough peer review by experienced researchers in your field

- rapid publication on acceptance

- support for research data, including large and complex data types

- gold Open Access which fosters wider collaboration and increased citations

- maximum visibility for your research: over $100 \mathrm{M}$ website views per year

At BMC, research is always in progress.

Learn more biomedcentral.com/submissions 